\title{
Editorial
}

\section{Children of Incarcerated Parents}

\author{
Marian S. Harris ${ }^{*} \S$ \\ University of Washington Tacoma, USA
}

This special issue of The Open Family Studies Journal includes four varied articles selected for publication from several submissions that addressed many issues and challenges relevant to the lives of children of incarcerated parents. The four articles are as follows: Caregivers of Children with Incarcerated Parents; Intergenerational Transmission of Criminal Behavior and Children of Incarcerated Parents; Please Remember Me: Unintended Consequences Children of the Incarcerated; and the Relationship between Maternal Incarceration and Foster Care Placement. The challenges posed to children and families of the incarcerated are quite significant. This special issue would not have been possible without the services of the reviewers. We would like to thank Drs Kathryn Basham, James Drisko, Jerry Finn, Rich Furman, Sheri Hill, Peter Pecora, Starr Wood, and Diane Young. Finally, we would like to thank Nida Badar for her patience, understanding and technical assistance as we slowly addressed the requirements for this special issue. This special issue focuses on children who have a birth mother and/or father incarcerated.

My interest in children of incarcerated parents started several years ago and peaked in 2008 when I developed and implemented a Family Reunification Group with a colleague, Dr. Kathryn Hamilton at a women's prison in Washington State. All of the incarcerated mothers in this group and their children were involved in the child welfare system. Although this group was designed specifically to be a psychotherapy group, many of the issues presented by the incarcerated mothers required the addition of an advocacy component. There were clear conflicts between the criminal justice system and the child welfare system. One of the major problems that we addressed was continued mother-child contact after incarceration because all of the mothers in the group still had their parental rights. I subsequently developed a course, Children of Incarcerated Parents that I teach in the Criminal Justice Program at the University of Washington Tacoma. There are a large number of students from varied disciplines who enroll in this course each year when it is taught.

On any given day, over 1.5 million children in this country have a parent incarcerated in a state or federal prison

\footnotetext{
*Address correspondence to this author at the University of Washington Tacoma, USA; Tel: (253) 692-4554; Fax: (253) 692-5825;

E-mail:mh24@u.washington.edu

${ }^{\S}$ Guest Editor
}

(The Annie E. Casey Foundation, n.d.) [1]. There are also millions of children who have a parent incarcerated in jail throughout the United States. According to a revised report from the U. S. Department of Justice (2010) [2], incarcerated parents reported having approximately 1,706,600 minor children in 2007; these children comprised $2.3 \%$ of the U.S. population under the age of eighteen. Parental incarceration impacts many facets of a child's life. Children experience emotional, social and financial deprivation when a parent is incarcerated. The attachment relationship is disrupted when a parent is incarcerated. It is important for children to maintain relationships with the incarcerated parent and to also have supportive relationships with extended family as well as other adults in their environment who can facilitate positive outcomes in their lives. However, there are several barriers that affect whether or not children maintain contact with an incarcerated parent including the policy of the facility where the parent is incarcerated, whether or not the facility is child-friendly, geographical location of the facility, the relationship between the incarcerated parent and the child's current caregiver and whether or not the child and incarcerated parent are involved with the child welfare system. Although many children and incarcerated parents are concurrently involved in the criminal justice and child welfare systems, these two systems often do not work in a cooperative/ collaborative manner to enhance life for children, incarcerated parents, kinship caregivers and foster parents. Children who are placed in foster care when a parent is incarcerated encounter additional problems as a result of child welfare law (1997 Adoption and Safe Families Act), policy and practice.

It is hoped that the four papers in this special issue will add to the growing body of research and literature regarding Children of Incarcerated Parents and the data, findings and other information are utilized to support and enhance the lives of children and their incarcerated parents, families and caregivers (kinship or foster).

\section{REFERENCES}

[1] The Annie E. Casey Foundation. (n.d.). Children of Incarcerated Parents Fact Sheet. Baltimore, MD: Author.

[2] US Department of Justice. Parents in prison and their minor children. Washington, DC: Author 2010.

(C) Marian S. Harris; Licensee Bentham Open.

This is an open access article licensed under the terms of the Creative Commons Attribution Non-Commercial License (http: //creativecommons.org/licenses/by$\mathrm{nc} / 3.0 /$ ) which permits unrestricted, non-commercial use, distribution and reproduction in any medium, provided the work is properly cited. 